\title{
Predictability of Zonal Means During Boreal Summer
}

\author{
Siegfried D. Schubert, Max J. Suarez, Philip J. Pegion' and Michael A. Kistler ${ }^{1}$ \\ Goddard Laboratory for Atmospheres, NASA/GSFC \\ Greenbelt, Maryland
}

Arun Kumar

Climate Modeling Branch, EMC, NCEP/NWS/NOAA

Washington, D.C.

April 11,2001

Submitted to J. Climate

\footnotetext{
'Addition affiliation: General Sciences Corporation, Beltsville, Maryland
} 


\begin{abstract}
This study examines the predictability of seasonal means during boreal summer. The results are based on ensembles of June-July-August (JJA) simulations (started in mid May) carried out with the NASA Seasonal-to-Interannual Prediction Project (NSIPP-1) atmospheric general circulation model (AGCM) forced with observed sea surface temperatures (SSTs) and sea ice for the years 1980-1999. We find that the predictability of the JJA extra-tropical height field is primarily in the zonal mean component of the response to the SST anomalies. This contrasts with the cold season (January-February-March) when the predictability of seasonal means in the boreal extratropics is primarily in the wave component of the EI Nino/Southem Oscillation (ENSO) response.
\end{abstract}

Two patterns dominate the interannual variability of the ensemble mean JJA zonal mean height field. One has maximum variance in the tropical/subtropical upper troposphere, while the other has substantial variance in middle latitudes of both hemispheres. Both are symmetric with respect to the equator. A regression analysis suggests that the tropical/subtropical pattern is associated with SST anomalies in the far eastern tropical Pacific and the Indian Ocean, while the middle latitude pattern is forced by SST anomalies in the tropical Pacific just east of the dateline. The two leading zonal height patterns are reproduced in model runs forced with the two leading JJA SST patterns of variability. A comparison with observations shows a signature of the middle latitude pattern that is consistent with the occurrence of dry and wet summers over the United States. We hypothesize that both patterns, while imposing only weak constraints on extratropical warm season continentalscale climates, may play a role in the predilection for drought or pluvial conditions. 


\section{Introduction}

It is well established that, during boreal winter, tropical sea surface temperature (SST) anomalięs associated with El Niño/Southerm Oscillation (ENSO) generate an atmospheric wave-like response that has a substantial impact on the variability over the North Pacific and North America (e.g., Wallace and Gutzler 1981; Palmer and Mansfield 1986; Livezey and Mo 1987). Furthermore, results from atmospheric general circulation model (AGCM) simulations forced with observed SSTs are consistent in showing that ENSO provides a potentially important source of predictability in the middle latitudes especially in the so-called Pacific/North American region (e.g., Barnett et al. 1994; Kumar and Hoerling, 1995; Shukla et al. 2000; Chang et al. 2000; Brankovic and Palmer 2000). The recent successful winter forecasts over North America for the $1997 / 98$ major ENSO event confirm the importance of ENSO for the seasonal to interannual prediction problem in the extratropics (van den Dool et al. 1999; Barnston et al. 1999).

In contrast with winter, AGCM forecast skill for the summer season over North America is small (e.g. Evans et al. 1997), and the nature of the link between tropical SST anomalies and extratropical climate variability and predictability is less clear. Ting (1994) shows that the North American climatological summer wave train in a GCM simulation is influenced indirectly by global diabatic heating through the nonlinear interaction between the heating-induced flow field and the Rocky Mountains and speculates that this mechanism may provide a link between variations in the

Asian and west Pacific heat source and rainfall over the United States. Trenberth et al. (1988) and Trenberth and Branstator (1992) link the 1988 drought over the United States to a northward displacement of the ITCZ associated with SST anomalies in the tropical Pacific. Ting and Wang (1997) show that Great Plains summer precipitation is associated with SST anomalies in both the tropical and North Pacific Ocean. They suggest that the link with the North Pacific SST is a feedback on the atmosphere from SST anomalies induced by the atmosphere in the first place. 
One of the difficulties in establishing the relationships between SST anomalies and summer continental precipitation variations is the importance of local processes and feedbacks associated with soil moisture, low level moisture transport and storm track changes (e.g. Namias 1991; Atlas et al. 1993; Helfand and Schubert 1995; Lyon and Dole 1995; Beljaars et al. 1996; Koster and Suarez 1995; Mo et al. 1997).

While many of the above-mentioned studies have generally focused on the wave response to SST anomalies, there is also evidence that zonally-symmetric changes may be an important component of extratropical variability and predictability. Ting et al. (1996) show that, during northern winter, a substantial fraction of the seasonal mean eddy height variability can be explained in a linear regression sense by a zonal mean zonal wind index that is independent of tropical SST variability. For northern summer, Erickson (1983) showed that the four warmest (coolest) summers over the United States during the period 1948-80, while showing considerable regional differences, tend to be associated with above (below) normal zonally averaged $700 \mathrm{mb}$ height anomalies throughout the middle and low latitudes. Remarkably, a further analysis of all 33 years showed that above normal temperatures over the United States are positively correlated with the zonally averaged $700 \mathrm{mb}$ height anomalies in tropical and subtropical latitudes during the previous seasons. Bamston (1994) found a similar link between $700 \mathrm{mb}$ height anomalies throughout the Northern Hemisphere lower latitudes $\left(20^{\circ} \mathrm{N}-40^{\circ} \mathrm{N}\right)$, and warm season surface temperature over the United States for the period 1955-1991. Bamston noted that this tends to occur during the summer following a mature ENSO event and following a spring with like-signed SST anomalies in the Pacific, Atlantic and Indian Oceans. Recently, Hoerling et al. (2000) found that the tropospheric height anomalies during 1998-2000 reflected pronounced warming at all latitudes between 30-50 degrees latitude of both hemispheres. They found that the anomalies are forced by SST anomalies that appear to be unrelated to the La Niña SST conditions and speculated on the role of SST anomalies in the Indo-Pacific warm-pool region. 
In this study, we re-examine the nature of the predictable signal during boreal summer based on an ensemble of seasonal AGCM simulations for the period 1980-1999. We focus on the predictability, variability, and forcing of the zonal-mean anomalies, and discuss their potential role in the development of regional climate anomalies.

Section 2 gives an overview of the ACM and model simulations. The results are presented in Section 3. Section 3a characterizes the signal and noise in the seasonal simulations and contrasts the boreal winter and summer seasons. The focus of section $3 \mathrm{~b}$ is on the boreal summer and the nature of the relationship between the anomalies in the zonal mean height and SSTs. Section 3c examines this link further with a series of seasonal simulations forced with idealized SST anomalies. The discussion and conclusions are given in section 4 .

\section{The AGCM and Simulation Experiments}

The model used in this study is the NASA Seasonal-to-Interannual Prediction Project (NSIPP-1) atmospheric-land general circulation model (AGCM). The model is part of the NSIPP coupled atmosphere-land-ocean model; however, for these experiments, it is run uncoupled from the ocean. The climate of NSIPP-1 and its formulation are described in Bacmeister et al. (2000). The predictability and skill of the model are described in Pegion et al. (2000) for boreal winter. A brief description of the model is given below.

The dynamical core of the NSIPP-1 AGCM is described in Suarez and Takacs (1995). NSIPP- 1 is a grid point model using the vector-invariant form of the momentum equation. A 4th-order Arakawa Jacobian with explicit leapfrog time differencing is used to integrate the momentum equations. Prognostic equations for moisture and potential temperature are integrated using a 4th-order space centered flux formulation in the horizontal with leapfrog time differencing. The vertical coordinate is a standard $\sigma$-coordinate and vertical 
differencing follows Arakawa and Suarez (1983). Vertical advection is accomplished using space-centered 2 nd-order differences.

The boundary layer scheme is a simple $\mathrm{K}$-scheme, which calculates turbulent diffusivities for heat and momentum based on Monin-Obukhov similarity theory (Louis et al., 1982). Turbulent diffusivities are determined as functions of roughness length, the von Karman constant, and a bulk boundary-layer Richardson number. Vertical mixing of tracers is accomplished using the diffusivity for heat.

The AGCM uses the relaxed Arakawa-Schubert (RAS) scheme to parameterize convection (Moorthi and Suarez, 1992). RAS uses a sequence of simple linearly-entraining plumes (cloud types) that originate and detrain at specific model levels. Each cloud type is characterized by an entrainment rate and a cloud-base mass flux. The characteristic entrainment rate is determined from the environmental stability profiles to ensure that plumes originating at the desired cloud-base will lose buoyancy, or detrain, at the desired detrainment level. The initial cloud-base mass flux for each cloud type is determined from a CAPE closure (Arakawa and Schubert, 1974), which, roughly speaking, specifies larger mass flux as moist convective instability increases. In our implementation of RAS, convection originates from the relatively-thin, lowest model layer $(\Delta \sigma=0.015)$, and can detrain into any layer above. Thus, we are in effect allowing RAS to act as a parameterization of both deep and shallow convection in our model. Bacmeister and Suarez (2001) show that the model produces a reasonable simulation of the thermodynamic structure of the lower troposphere.

The parameterization of solar and infrared radiative heating used in the model is described in Chou and Suarez $(1994,1999)$. The solar heating includes absorption by $\mathrm{O}_{3}, \mathrm{CO}_{2}$, water vapor, $\mathrm{O}_{2}$, and clouds as well as gaseous and aerosol scattering. The solar spectrum is divided into eight visibleUV bands and three near-IR bands. A k-distribution method is used within each band. The eight 
visible-UV bands use a single k-interval, while the near-IR bands use ten intervals each. Effects of multiple scattering by clouds and aerosols are treated using the $\delta$-Eddington approximation for the direct beam and the Sagan-Pollock approach for diffuse radiation.

The simulations described here use a uniform horizontal resolution of $2^{\circ}$ latitude $\mathrm{X} 2.5^{\circ}$ longitude and 34 unequally spaced $\sigma$-layers with high resolution $(<200 \mathrm{~m})$ in the lower $2 \mathrm{~km}$ of the atmosphere. The simulations consist of nine 105-day runs for each year for the period 1980-1999. While we have performed these simulations for all seasons, we focus our attention here on boreal summer; however, we also show some winter results to help highlight the differences between the warm and cold seasons. The summer runs were started in mid May and run through to the end of August, and we analyze the June-July-August (JJA) means. The winter runs started in midDecember and were run through to the end of March, and we analyze the January-February-March (JFM) means. The fact that our winter simulations are for JFM instead of the standard winter months (December-January-February) was dictated by our participation in the Dynamical Seasonal Prediction Project (DSP, Shukla et al. 2000). For each year, the model atmosphere was initialized from the National Centers for Environmental Prediction/National Center for Atmospheric Research (NCEP/NCAR, Kalnay et al. 1996) reanalysis, with each ensemble member differing only in the starting time (separated by 12 hours, centered on mid-month).

The SSTs are the monthly mean values of Reynolds and Smith (1994). The initial soil wetness is taken from a previously completed long multi-year model simulation forced by observed SST over the same time period. In particular, for the winter simulations the initial soil wetness was taken from an arbitrary December I state from the long model simulation, so that it is the same for all years and all ensemble members. For the summer simulations, instead of using the same initial soil moisture for all runs, we chose instead to take the May 1 soil wetness from the multi-year integration for the appropriate year. In this way, any soil moisture variations driven by the SST in 
the long simulations are allowed to contribute to the skill through the soil initial conditions. Note, however, that in this approach all ensemble members for any one year have the same initial soil wetness, so we implicitly assume that the initial soil moisture is perfectly known. We will retum to that point later in our discussion of the impact of the soil wetness anomalies.

\section{Results}

The results are organized as follows. Section 3a compares the signals of the height field for the two seasons (JFM and JJA). This is followed in section 3 b by a focus on JJA and a diagnostic analysis of the structure and forcing of the zonal mean height variability. Section $3 c$ describes the results of further AGCM simulations with idealized SST anomalies that seek to confirm and clarify the diagnosed relationships between the dominant patterns of JJA SST variability and height anomalies. That section also examines the global distribution of the precipitation signal forced by the SST patterns.

\section{a) The signals in JFM and JJA height fields}

We begin by examining the signals in the seasonal mean (JFM and JJA) simulations for 19801999. The total variance of the seasonal mean of a quantity $(x)$ is divided into contributions from the signal (the ensemble mean) and noise (the variations about the ensemble mean) as follows. An unbiased estimate of the variance of the signal (the inter-ensemble variance, see e.g., Rowell et al. 1995) is

$$
s_{g}^{2}=\frac{n}{n-1}\left[(\bar{x}-[\bar{x}])^{2}\right]-\frac{1}{m} s_{w}^{2} .
$$


Here the over-bar denotes a mean over the $m=9$ ensemble members, the square brackets denote a mean over the $n=20$ seasons, and the subscript $g$ indicates that the variance is associated with the signal. The second term on the right hand side of (1) is proportional to the variance of the noise (indicated by subscript $w$ ) and ensures that the estimate of the variance of the signal is unbiased. An unbiased estimate of the variance of the noise is

$$
s_{w}^{2}=\frac{m}{m-1}\left[\overline{(x-\bar{x})^{2}}\right]
$$

In the following figures, we present the standard deviation of the signal $\left(s_{g}\right)$ and the ratio of the variance of the signal to the total variance define as

$$
T=\frac{s_{g}^{2}}{s_{w}^{2}+s_{g}^{2}} .
$$

Completely analogous expressions are obtained for the variance of the zonal mean. In this case, the variance of the signal, the variance of the noise, and the ratio of the variance of the signal to the total variance are designated by $s z_{g}^{2}, s z_{w}^{2}$, and $T_{z}$, respectively.

Figure 1 shows $s_{g}$ and $T$ for both seasons. During JFM, the signal (top left panel of Fig. 1) is dominated by the large interannual variability over the eastern tropical and North Pacific Ocean associated with the ENSO SST anomalies. Substantial signals also occur over parts of North America, the North Atlantic and the North Polar regions. In contrast, during JJA (top right panel of Fig. 1) the largest signal occurs over the South Pacific (the winter hemisphere), while the Northern Hemisphere is characterized by much smaller signals. The ratio of the signal to total variance ( $T$, bottom panels of Fig. 1) is largest throughout the tropics and drops rapidly as one moves into the subtropics and middle latitudes. Comparing $T$ for the two seasons, we find ratios 
with surprisingly similar magnitudes in the extratropics, though the spatial distribution of the JJA ratios is much more zonal. The similarity in the magnitude of the ratios is an indication that the reduction in the signal during JJA is accompanied by a reduction in the noise. Therefore, predictability, as measured by the signal to total variance ratio, is comparable during these two seasons, though it remains to be seen whether this translates to useful forecast skill during JJA.

The nature of the potentially predictable signal is seen more clearly in Figure 2 . In the top panels of that figure we show the standard deviation of the signal for the two seasons after removing the variance of the signal in the zonal mean ${ }^{2}$ :

$$
s e_{g}^{2} \equiv s_{g}^{2}-s z_{g}^{2}
$$

We also define the corresponding signal to total ratio

$$
T_{e}=\frac{s e_{g}^{2}}{s_{w}^{2}+s_{g}^{2}}
$$

The ENSO component of the signal is clearly evident in $s \epsilon_{g}$ over the eastern Pacific and North America during JFM (top left panel of Fig. 2). In contrast, during JJA little signal remains after subtracting the zonal contribution, and what does remain is confined to the southern Pacific Ocean (top right panel of Fig. 2). Similarly, the largest values of $T_{e}$ (bottom panels of Figure 2) are for the most part confined to the tropics and winter hemisphere Pacific Ocean.

\footnotetext{
2 We note that this is not an exact partition of the total variance into zonal and eddy components, since in general the eddy and zonal contributions are correlated and there would be cross product terms. In fact, there are small negative values in $s e_{g}^{2}$ that are suppressed in the plots.
} 
Figure 3 shows the standard deviation of the signal in the zonal mean height $\left(s z_{g}\right)$ and the signal to total variance for the zonal means $\left(T_{z}\right)$. The signal again tends to be stronger in the winter hemisphere though, for the zonal means, the Southern Hemipshere shows less seasonal dependence in the strength of the signal. In the northern hemisphere, the signal is clearly larger during JFM, however, the ratio of signal to total variance $\left(T_{z}\right)$ drops off rapidly away from the equator so that north of $20^{\circ} \mathrm{N}$ the ratio is generally less than 0.5 . During JJA, however, the ratio remains greater than 0.5 well into the middle latitudes, confirming that most of the potentially predictable variance for JJA is in the zonal mean component.

\section{b) The JJA zonal mean anomalies}

In the previous section we found that the zonal mean is one of the most predictable features of the JJA height variance. In this section we focus on the nature of the JJA ensemble mean zonal mean height variance. Figure 4 shows the two leading rotated empirical orthogonal functions (EOFs) computed from the variance/covariance of the ensemble mean zonal mean JJA height field based on the 20-year period 1980-1999. The first pattern has maximum variance in the upper troposphere near $200 \mathrm{mb}$ and it is centered on the equator. It is largely symmetric with respect to the equator except at high latitudes where it tends to be of opposite sign in the two hemispheres. The second pattern also tends to be symmetric with respect to the equator with maximum variance again near $200 \mathrm{mb}$ but located between $30^{\circ}$ and $60^{\circ}$ latitude in both hemispheres. These two patterns explain $34 \%$ and $20 \%$, respectively, of the variance of the signal in the zonal mean, $s z_{g}^{2}$.

Figure 5 shows the correlation of the time series associated with the first two zonal mean height EOFs (the principal components or PCs) with SST at each grid point. For PC 1, the largest correlations occur over the Indian Ocean and far eastern tropical Pacific Ocean. For PC 2, positive correlations occur just east of the dateline over the tropical Pacific, while negative correlations 
occur over the western Pacific and parts of the Atlantic Ocean (the equator and the northem middle latitudes). This suggests that the two zonal mean height EOFs are forced by very different SST patterns. Figure 6 shows, in fact, that these two correlation patterns bear a strong resemblance to the two dominant JJA SST EOFs (compare Figures 5 and 6). The time series of the PCs associated with the first two SST is shown in Figure 7. The first PC has large positive values during the El Nino summers of 1983,87 , and 97 , and negative values during the La Nina summers of 1985,88 and 99 . PC 1 also reflects, in part, the unprecedented warming that occurred in the Indian Ocean beginning in July of 1997. PC 2 shows positive values during the summers of 1982,86 , during the extended warm conditions of the first half of the 1990 s, and 1997. Large negative values occur in 1984, 88, 98 and 99.

Further evidence for a strong link between the leading SST EOFs and the zonal mean height variability is obtained by regressing the zonal mean ensemble mean height against the SST PCs. Figure 8 shows that the regression essentially reproduces the EOF patterns discussed earlier (compare Figure 4 and Figure 8). The results are displayed to show the zonal mean change associated with a 2 standard deviation change in the SST EOFs. Figure 9 shows the local link between the SST EOFs and the height variance obtained by regressing the $200 \mathrm{mb}$ ensemble mean height variance at each grid point against the SST EOFs. This shows clearly that the signals associated with the two leading SST EOFs do indeed have a strong zonally-symmetric component. The largest height changes associated with EOF 1 occur over the eastern tropical Pacific and tropical Indian Oceans (top panel of Fig. 9). The bottom panel of Fig. 9 shows that, while there is strong zonal symmetry associated with EOF 2, there is also a substantial wave component over the southern Pacific Ocean (c.f. Figure 3).

It is difficult to directly assess the realism of the model-generated height variability associated with the SST EOFs (e.g. those in Figure 9) since we cannot generate ensemble mean fields from the observations (there is only one realization from nature!). Nevertheless, we can carry out the 
analogous regressions against the two leading SST EOFs using, instead of the ensemble mean, the single case provided by nature. Figure 10 is the same as Figure 9, except using the single realization of nature as estimated from the NCEP/NCAR reanalysis. While considerably noisier than the results shown in Figure 9, the same basic patterns stand out, indicating that the model is producing quite realistic results.

Figure 11 shows examples of the model simulations and the reanalysis fields for two summers that experienced extreme hydrological conditions over the United States: the 1988 drought and the 1993 floods. The second pattern clearly stands out in the simulations during these two years, showing a tendency for enhanced heights in middle latitudes of both hemispheres during the U.S. drought and reduced heights during the U.S. floods. The reanalysis shows similar signatures of the second pattern, though there is considerably more eddy structure (for example associated with the drought and flood over the U.S.). The U.S. rainfall from the model runs for these 2 years (not shown) show little agreement with observations. The model results do show a general tendency for wet conditions over the U.S. during 1993, though during 1988 there is a rather mixed spatial pattern of both dry and wet conditions. These results, however, depend on our choice of the initial soil moisture (taken from a long simulation as described earlier) and therefore they are not a clear indication of the direct role of the SST anomalies. We will return to the issue of how the SST impact the rainfall in the next section.

\section{c) Idealized SST Model runs}

In order to further strengthen the connection between the first two height patterns (Figure 9) and the first two SST pattems (Figure 6), we carried out a series of seasonal (JJA) simulations in which the model is forced with idealized SST anomalies whose spatial structures correspond to the two leading SST EOFs shown in Figure 6. In particular, we produced four ensembles of $10 \mathrm{JJA}$ simulations by starting the runs from 10 different May 1 atmospheric and land surface initial 
conditions (chosen from different years of two long model simulation). Each ensemble of runs used the same 10 initial conditions. The four ensembles are distinguished by having different SST forcing. The four SST anomaly maps are produced by multiplying the two leading EOF patterns by the positive and negative of the largest projection of the mode during the 20 -year period $(+1-33$ for EOF 1, and +/-28 for EOF 2). Locally, the imposed SST anomalies (not shown) corresponding to EOF 1 have maximum magnitudes of about $1^{\circ} \mathrm{C}$ in the Indian Ocean and exceed $2^{\circ} \mathrm{C}$ only in the extreme eastern tropical Pacific, while for EOF 2 the eastern tropical Pacific Ocean has SST anomalies with magnitudes between $1^{\circ}$ and $2^{\circ} \mathrm{C}$.

Figure 12 shows the ensemble mean of the forcing experiments in terms of the difference of the responses to the two polarities of each SST EOF. While there are some asymmetries between the responses to the two SST forcing polarities (not shown), these are generally small. Comparing Figure 12 with Figure 9, we find a remarkable degree of similarity between the forced experiments and the results of the regression, confirming that these two height patterns are indeed forced by the two SST anomaly patterns. Furthermore, this suggests that these patterns represent basically linear responses to the SST forcing.

Figure 13 shows the precipitation anomalies from the SST forcing experiments. We discuss the results in terms of the positive polarities (warm phase) of the EOF SST anomalies corresponding to the patterns shown in Figure 6. For the positive polarity of EOF 1, the precipitation is enhanced over the Indian Ocean, much of the eastern tropical Pacific, the North Pacific storm track, and parts of the Atlantic. Reduced precipitation occurs over the South Pacific Convergence Zone (SPCZ) and in a narrow band across the entire eastem tropical Pacific just to the north of the enhanced precipitation noted earlier. This north-south anomaly pattern in the eastern Pacific suggests an equatorward shift in the ITCZ. For the positive polarity of EOF 2, the maximum precipitation anomaly occurs at the equator just west of the dateline. The precipitation is also enhanced in the Southern Hemisphere in a band extending from the central South Pacific across southem South 
America. In the northem extratropics, the precipitation is enhanced to the north and east of the Mediterranean Sea, and over northern Mexico extending into the central Great Plains of the United States.

We note that, precipitation anomalies very similar to those in Figure 13 are obtained by regressing the ensemble mean precipitation from the 1980-1999 JJA simulations against the two leading SST EOFs (results not shown). This allows us to validate the model's precipitation response (Figure 13) to the imposed SST anomalies by comparing it with the anomalies obtained by regressing the observed JJA precipitation (Xie and Arkin 1996) against the two leading SST EOFs. The regression results (Figure 14) show basic large-scale anomaly patterns that are quite similar to those from the forced model runs (Figure 13). In the following, we discuss the results in terms of the positive phase of the EOFs shown in Figure 6. For example, the regression against EOF 1 (top panel Figure 14) showing a southward shift in the Pacific ITCZ, reduced precipitation over the SPCZ, enhanced precipitation over the Indian Ocean, enhanced precipitation in the Pacific Storm track, and a northward shift in the Atlantic ITCZ, are similar to what was found for the model results. The regression against EOF 2 (bottom panel Figure 14) also shows substantial similarities with the corresponding results from the model (bottom panel of Figure 13). In particular, the positive tropical precipitation anomalies extending from just west of the dateline into the eastern tropical Pacific, the positive anomalies in the eastern South Pacific extending across southem South America, and the negative precipitation anomalies over the tropical Indian and Atlantic Oceans, are all similar to those found for the forced model results.

The northem hemisphere extratropical continental precipitation is apparently only weakly constrained by the JJA SST anomalies. This is true for both the observations (Figure 14) and the model results (Figure 13). The model does show significant precipitation anomalies extending from Southern Europe to the Caspian Sea associated with EOF 2, though this is not true for the observations. Both the model and observations suggest enhanced(reduced) precipitation in the 
central United States associated with the positive(negative) phase of SST EOF 2 (lower panels of Figures 13 and 14, see also Figure 11). A further analysis of the model results (not shown) suggests that the central United States precipitation is impacted by changes in the easterlies forced by the heating anomalies in the tropical eastern Pacific. The change in the easterlies leads to changes in the low level winds that are diverted northward to transport water from the Gulf of Mexico into the central United States. The southerly low level wind and, in particular, the Low Level jet in the Great Plains is well known to be a major contributor to the moisture budget of the central United States (Helfand and Schubert 1995).

\section{Discussion and Conclusions}

Recent ENSO events have helped to underscore the importance of tropical SST anomalies in the seasonal prediction problem for North America during Northern winter. On the other hand, AGCM forecast skill for the summer season over North America is substantially less (e.g. Evans et al. 1997), and the nature of the link between tropical SST anomalies and extratropical climate variability and predictability is less clear. The current study re-examines JJA predictability, based on a series of seasonal simulations with the NASA Seasonal-to-Interannual Prediction Project (NSIPP-1) atmospheric general circulation model (AGCM) forced by observed sea surface temperatures (SSTs).

Similar to previous results we find that, in the absence of soil moisture information, there is little predictability in the JJA northern extratropics regional climate anomalies associated with the eddy response to the El Nino/Southern Oscillation (ENSO) forcing. We did find, however, that the zonal mean component is potentially predictable well into middle latitudes of both hemispheres. This contrasts with the cold season (January-February-March) when, in the boreal extratropics, the predictability of seasonal means is primarily in the wave component of the ENSO response. 
An EOF analysis of the JJA zonal mean height field showed that the variance of the ensemble mean is dominated by two pattems which are largely symmetric with respect to the equator. The first has maximum variance in the tropical upper troposphere, while the second has substantial variance in middle latitudes of both hemispheres. A regression analysis showed that the first of these is forced by SST anomalies in the far eastern tropical Pacific and the Indian Ocean, while the second pattern is forced by SST anomalies in the tropical Pacific extending eastward from the dateline. This was confirmed by a series of model simulations that were forced with SST anomalies consisting of the first two SST,EOF patterns.

The signature of these zonal patterns is evident in the results of several previous studies. For example, Erickson (1983) found that above normal temperatures over the United States for the period 1948-80 are positively correlated with the zonally averaged $700 \mathrm{mb}$ height anomalies in tropical and subtropical latitudes during the previous seasons. Barnston (1994) found a link between $700 \mathrm{mb}$ height anomalies throughout the Northern Hemisphere lower latitudes $\left(20^{\circ} \mathrm{N}\right.$ $40^{\circ} \mathrm{N}$ ), and warm season surface temperature over the United States for the period 1955-1991. Hoerling et al. (2000) found that the tropospheric height anomalies during 1998-2000 showed pronounced warming at all latitudes between 30-50 degrees latitude of both hemispheres. In fact, the 1999 annual mean average height anomalies (see their Figure 2) look remarkably like our height anomalies associated with SST EOF 2 (cf. bottom panel of Figure 9). Their results show that these patterns are not confined to the boreal summer season, though our results suggest that the predictability of the zonally-symmetric patterns is higher during the summer season.

We suggest further that the general tendency for dry or wet conditions in middle latitudes may be controlled by the zonally-symmetric patterns, particularly the second pattern (Figure 9, bottom panel) which has most of its variance in middle latitudes. For example, the global signature of the second pattern is clearly evident during the 1988 drought and 1993 floods in the United States. The controls on the extratropical precipitation by this SST anomaly pattern are, however, weak, so 
that the strength and timing of specific drought and flood events must be influenced by other SST anomalies or by other factors. For example, the 1988 SST anomalies in the eastern tropical Pacific appear to have been important for shifting the ITCZ to the north and generating a wave response over North America that led to the U.S. drought conditions as suggested by Trenberth et al. (1988) and Trenberth and Branstator (1992). In our results, the first SST EOF forces a north-south shift in the Pacific ITCZ (see top panels of Fig. 13 and 14). While this pattern did contribute to the 1988 SST anomalies (see Fig.7), it does not appear to have much influence on the precipitation over the United States.

The other key factor in the forcing of drought and flood events is soil moisture. While we have not addressed this issue here, numerous studies have shown that soil moisture anomalies play an important role in the development and maintenance of drought and flood conditions (e.g. Namias 1991; Atlas et al. 1993; Beljaars et al. 1996); this appears to be especially true in continental regions, such as the United States Great Plains, which are transition zones between dry and wet climates (Koster et al. 2000).

Acknowledgements: This work was supported by the NASA Earth Science Enterprise's Global Modeling and Analysis Program, and the NASA Seasonal-to-Interannual Prediction Project. 


\section{References}

Arakawa, A. and M.J. Schubert, 1974: Interaction of a cumulus cloud ensemble with the large scale environment, Part I, J.Atmos.Sci., 31, 671-701.

Arakawa, A. and M.J. Suarez, 1983: Vertical differencing of the primitive equations in sigma coordinates. Mon. Wea. Rev., 111, 34-45.

Atlas, R., N. Wolfson and J. Terry, 1993: The effect of SST and soil moisture anomalies on the GLA model simulations of the 1988 U.S. drought. J. Climate, 6, 2034-2048.

Bacmeister, J., P.J. Pegion, S. D. Schubert, and M.J. Suarez, 2000: An atlas of seasonal means simulated by the NSIPP 1 atmospheric GCM, NASA Tech. Memo. No. 104606, volume 17, Goddard Space Flight Center, Greenbelt, MD 20771, 2000.

Bacmeister, J. T. and M.J. Suarez, 2001: Wind stress simulations and equatorial dynamics in an AGCM. Part I: Basic results from a 1979-1999 forced SST experiment.

Submitted to J. Atmos. Sci.

Barnett, T.P., L. Bengtsson, K. Arpe, M. Flugel, N. Graham, M. Latif, J. Ritchie, E. Roecker, U. Schlese, U. Schultzweida, and M. Tyree, 1994: Forecasting global ENSO-related climate anomalies. Tellus, 46A, 381-397.

Barnston, A.G., 1994: Linear statistical short-term climate predictive skill in the Northern Hemisphere. J. Climate, 7, 1513-1564. 
Barnston, A. G., A. Leetmaa, V. E. Kousky, R. E. Livezey, E. O'Lenic, H. M. van den Dool, A. J. Wagner, and D. A. Unger, 1999: NCEP forecasts of the El Nino of 1997/98 and its U.S. impacts. Bull. Amer. Meteor. Soc., 80, 1829-1852.

Beljaars, A.C.M., P. Viterbo, M.J. Miller, and A.K. Betts, 1996: The anomalous rainfall over the United States during July 1993: Sensitivity to land surface parameterization and soil moisture anomalies, Mon. Wea. Rev., 124,362-383.

Brankovic, C. and T.N. Palmer, 2000: Seasonal skill and predictability of ECMWF PROVOST ensembles. Quart. J. Roy. Met. Soc., 126, 2035-2067.

Chang, Y., S.D. Schubert, M.J. Suarez, 2000: Boreal winter predictions with the GEOS-2 GCM: The role of boundary forcing and initial conditions. Quart. J. Roy. Met. Soc., 126, 2293-2321.

Chou, M.-D., and M. J. Suarez, 1994: An efficient thermal infrared radiation parameterization for use in general circulation models. NASA Tech. Memo. 104606, Vol. 3, NASA Goddard Space Flight Center, Greenbelt, MD 20771. Available on-line from http://dao.gsfc.nasa.gov/subpages/tech-reports.html

Chou, M.-D. and M. J. Suarez, 1999: A solar radiation parameterization for atmospheric studies, NASA Technical Memorandum, 104606, 11, 40pp.

Erickson, C. O., 1983: Hemispheric anomalies of $700 \mathrm{mb}$ height and sea level pressure related to mean summer temperature over the United States. Mon. Wea. Rev., 111, 545-561. 
Evans, R.E., A.D.L. Evans, R.J. Graham and M.S.J. Harrison, 1997: Seasonal Predictability Experiments. Proceedings of the 22rd Annual Climate Diagnostics and Prediction Workshop, Oct. 6-10, 1997, Berkeley, California. pp370.

Helfand and S. D. Schubert, 1995: Climatology of the Simulated Great Plains Low-Level Jet and its Contribution to the Continental Moisture Budget of the United States. J. Climate, 8, 784-806.

Hoerling, M.P. A. Kumar, J. Witaker, and W. Wang, 2000: The midlatidue tropospheric warming during 1998-2000. Submitted to Geo. Res. Let.

Kalnay, E., and Coauthors, 1996: The NCEP/NCAR 40-year reanalysis project. Bull. Amer.Meteor.Soc., 77, 437-471.

Koster, R.D. and M.J. Suarez, 1995: The relative contributions of land and ocean processes to precipitation variability. J. Geophys. Res., 100, 13775-13790.

Koster R.D., M.J. Suarez, M. Heiser, 2000: Variance and predictability of precipitation at seasonal-to-interannual timescales. J. Hydrometeor., 1, 26-46.

Kumar, A. and M. P. Hoerling, 1995: Prospects and limitations of seasonal atmospheric GCM predictions. Bull. Amer. Meteor. Soc., 76, 335-345.

Livezey, R. E. and K. C. Mo, 1987: Tropical-extratropical teleconnections during the Northern Hemisphere winter. Part II: Relationships between monthly mean Northem Hemisphere circulation patterns and proxies for tropical convection. Mon. Wea.. Rev., $115,3115-3132$. 
Louis, J., M. Tiedtke, J. Geleyn, 1982: A short history of the PBL parameterization at ECMWF, in Proceedings, ECMWF Workshop on Planetary Boundary Layer

Parameterization, Reading, U. K., 59-80.

Lyon, B. and R.M. Dole, 1995: A diagnostic comparison of the 1980 and 1988 U.S. summer heat wave-droughts. J. Climate, 8, 1658-1676.

Mo, K.C., J. Nogues-Paegle, and R.W. Higgins, 1997: Atmospheric processes associated with summer floods and droughts in the central United States. J.Climate Sci., 10, 3028-3046.

Moorthi, S. and M. J. Suarez, 1992: Relaxed Arakawa-Schubert: A parameterization of moist convection for general circulation models. Mon. Wea. Rev., 120, 978-1002.

Namias, J., 1991: Spring and summer 1988 drought over the contiguous United States - Causes and prediction. J. Climate, 4, 54-65.

Palmer, T. N., and D.A. Mansfield, 1986: A study of wintertime circulation anomalies during past El Nino events using a high resolution general circulation model II: Variability of the seasonal mean response. Quart. J. Roy. Meteor. Soc., 112, 639-660.

Pegion, P.J., S. D. Schubert, and M.J. Suarez, 2000: An assessment of the predictability of northern winter seasonal means with the NSIPP I AGCM, NASA Tech. Memo. No. 104606, volume 18, Goddard Space Flight Center, Greenbelt, MD 20771, 2000.

Reynolds, W. R. and T. M. Smith, 1994: Improved global sea surface temperature analyses using optimum interpolation. J. Climate, 7, 929 -948. 
Rowell, D. P., C. Folland, K. Maskell, and N. Ward, 1995: Variability of summer rainfall over tropical north Africa (1906-92): Observations and modeling. Q.J.R.Meteor.Soc., 121, 669-704.

Shukla, J., J. Anderson, D. Baumhefner, C. Brankovic, Y. Chang, E. Kalnay, L. Marx, T. Palmer, D. Paolino, J. Ploshay, S. Schubert, D. Straus, M. Suarez, and J. Tribbia, 2000: Dynamical Seasonal Prediction, Bull. Amer. Met. Soc., 81, 2593-2606.

Suarez, M. J. and L. L. Takacs, 1995: Documentation of the Aries-GEOS Dynamical Core:Version 2. NASA Tech. Memo. No. 104606, volume 5, Goddard Space Flight Center, Greenbelt, MD 20771.

Ting, M., 1994: Maintenance of northern summer stationary waves in a GCM. J. Atmos. Sci., 51,3286-3308.

Ting, M., M.P. Hoerling, T. Xu, and A. Kumar, 1996: Northern Hemisphere teleconnection patterns during extreme phases of the zonal-mean circulation. J. Climate, 9, 2614-2633.

Ting, M. and H. Wang, 1997: Summertime U.S. precipitation variability and its relation to Pacific Sea Surface Temperature, J. Climate, 10,1853-1873.

Trenberth, K.E., G.W. Branstator and P.A. Arkin, 1988: Origins of the 1988 North American drought. Science, 242, 1640-1645.

Trenberth, K.E. and G.W. Branstator, 1992: Issues in establishing causes of the 1988 drought over North America. J. Climate, 5, 159-172.

Van den Dool, H. M., J. Hoopingarner, E.O'Lenic, A.J.Wagner, A.G.Barnston, R.E.Livezey, D.Unger, A.Artusa and R.Churchill, 1999: Third Annual review of skill of 
CPC real time long lead predictions: How well did we do during the great ENSO event. Proceedings of the 23rd Annual Climate Diagnostics and Prediction Workshop, Oct. 2630, 1998, Miami, Florida. U.S. Department of Commerce, NOAA/NWS/NCEP/CPC $336 \mathrm{pp}$.

Wallace, J. M., and D. S. Gutzler, 1981: Teleconnections in the geopotential height field during the Northern Hemisphere winter. Mon. Wea. Rev., 109, 784-812.

Xie, P. and P. Arkin, 1996: Analyses of global monthly precipitation using gauge observations, satellite estimates and numerical model predictions. J. Climate, 9, 840-858. 


\section{List of Figures}

Figure 1: Top panels: The standard deviation of the signal in the seasonal forecasts of the $200 \mathrm{mb}$ height field ( $s_{x}$ in text) for January-February-March (JFM, left panel), and June-July-August (JJA, right panel) computed for the period 1980-99. Units are meters. Lower panels: The variance of the signal divided by the total variance of the $200 \mathrm{mb}$ height ( $T$ in text) for JFM (left panel) and JJA (right panel).

Figure 2: Top panels: Same as Fig.1, except for the standard deviation of the signal after removing the variance of the zonal mean $\left(s e_{g}\right.$ in text). Lower panels: Same as Figure 1, except for the variance of the signal (after removing the variance of the zonal mean) divided by the total variance ( $T_{e}$ in text). Negative values are suppressed in the plots. See text for details.

Figure 3: Top panels: The standard deviation of the signal in the seasonal forecasts of the zonal mean height field ( $s z_{g}$ in text) for January-February-March (JFM, left panel), and June-JulyAugust (JJA, right panel) computed for the period 1980-99. Units are meters. Lower panels: The ratio of the signal to the total variance of the zonal mean height ( $T_{2}$ in text) for JFM (left panel) and JJA (right panel).

Figure 4: The first two (of five) rotated empirical orthogonal functions (EOFS) of the zonal mean ensemble mean height field for June-July-August of 1980-99. Units are arbitrary.

Figure 5: The correlation between the ground temperature (sea surface temperature) and the first principal component (top panel) and second principal component (bottom panel) of the zonal mean height EOFs for June-July-August of 1980-99. Shading indicates significance at the 5\% level. 
Figure 6: The first two (of five) rotated empirical orthogonal functions (EOFS) of the June-JulyAugust sea surface temperature (SST) for 1980-99. Units are arbitrary.

Figure 7: The principal component time series (June-July-August, 1980-99) associated with the first two SST EOFs shown in Figure 6. Units are arbitrary.

Figure 8: Results of regressing the ensemble mean zonal mean height field against the first two SST principal components (PCs) shown in Figure 7. The values plotted correspond to a positive two-standard deviation change in the SST PC predictors. Shading indicates the regression is significant at the $5 \%$ level. Units are in meters.

Figure 9: Same as Figure 8, except for the ensemble mean $200 \mathrm{mb}$ height field.

Figure 10: Same as Figure 9, except for the $200 \mathrm{mb}$ height field from the NCEP/NCAR reanalysis.

Figure 11: The JJA height anomalies at 200mb for 1988 (upper panels) and 1993 (lower panels), using a base period climatology of 1980-99. The left panels show the results of the 9-member ensemble mean of the model simulations. The right panels show the results from the NCEP/NCAR reanalyses. Units are meters.

Figure 12: The JJA ensemble mean $200 \mathrm{mb}$ height response of the AGCM to specified SST anomalies consisting of the first EOF (top panel) and second EOF (bottom panel) patterns shown in Figure 6. The results shown are the differences of the responses to the two polarities of each SST EOF divided by two. See text for details. Shading indicates significance at the $5 \%$ level. Units are meters.

Figure 13: Same as Figure 12, except for precipitation. Units are $\mathrm{mm} /$ day. 
Figure 14: Same as Figure 10, except for observed precipitation from Xie-Arkin (1996). Units are $\mathrm{mm} /$ day. Shading indicates the regression is significant at the $10 \%$ level. 

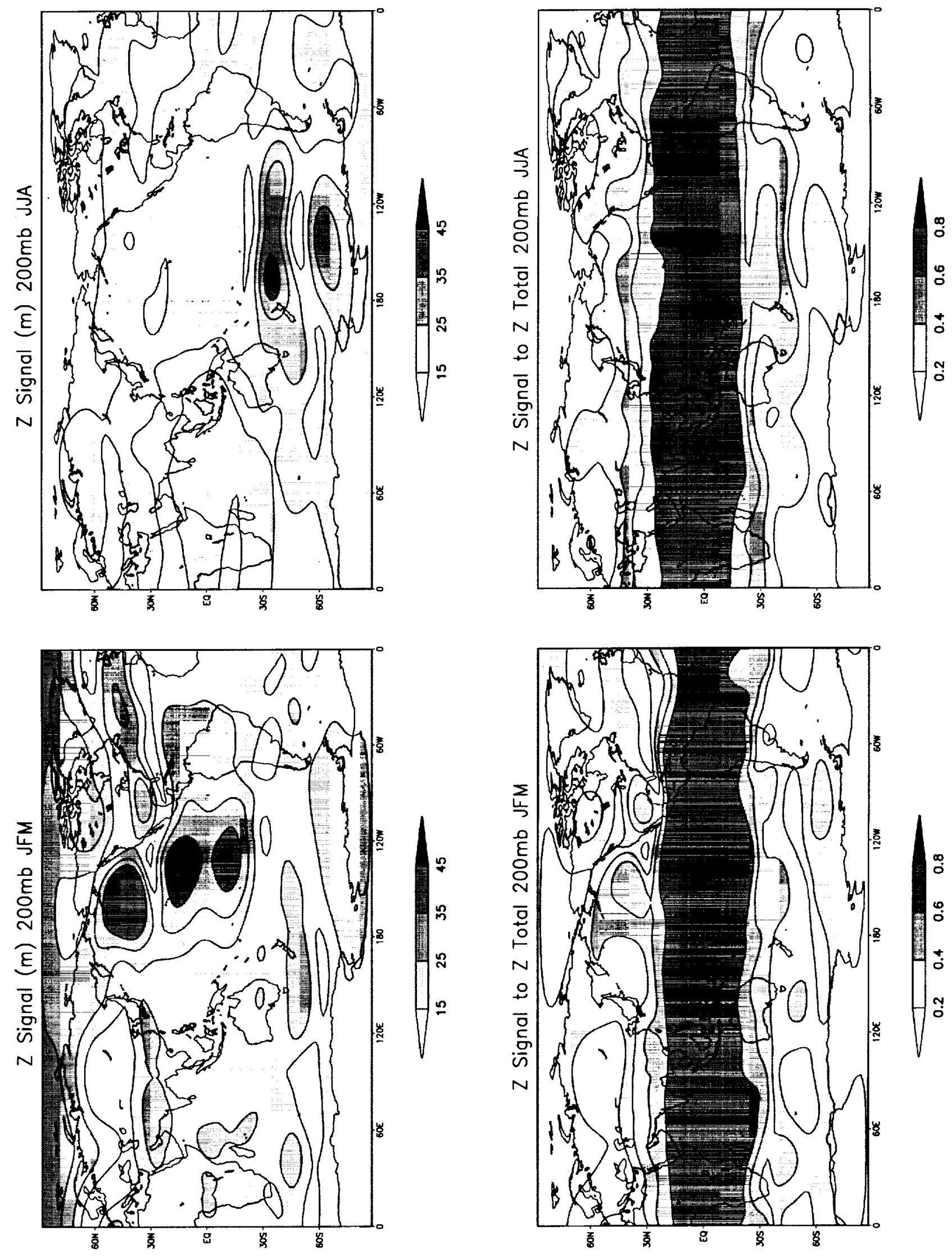

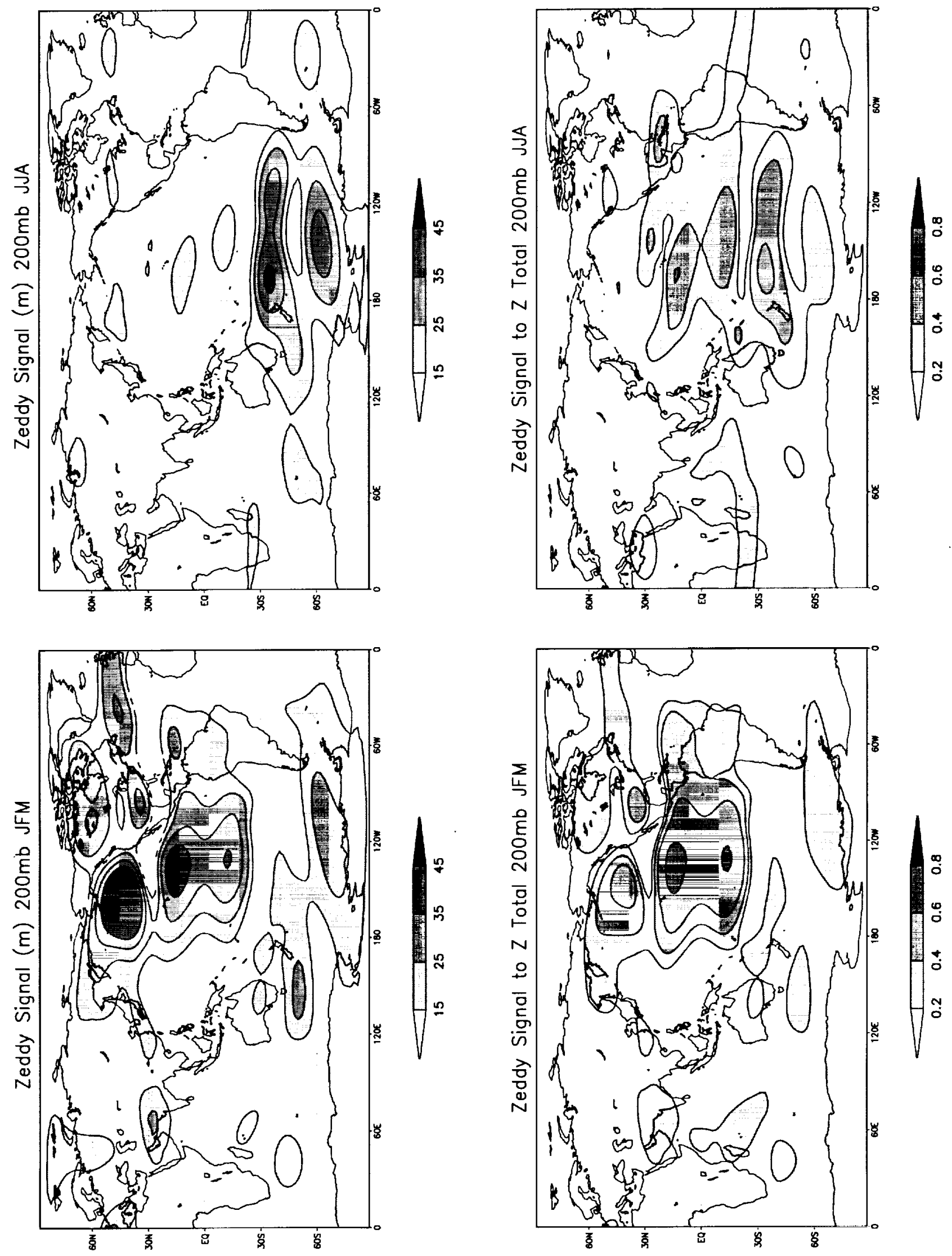

Fig, 2 

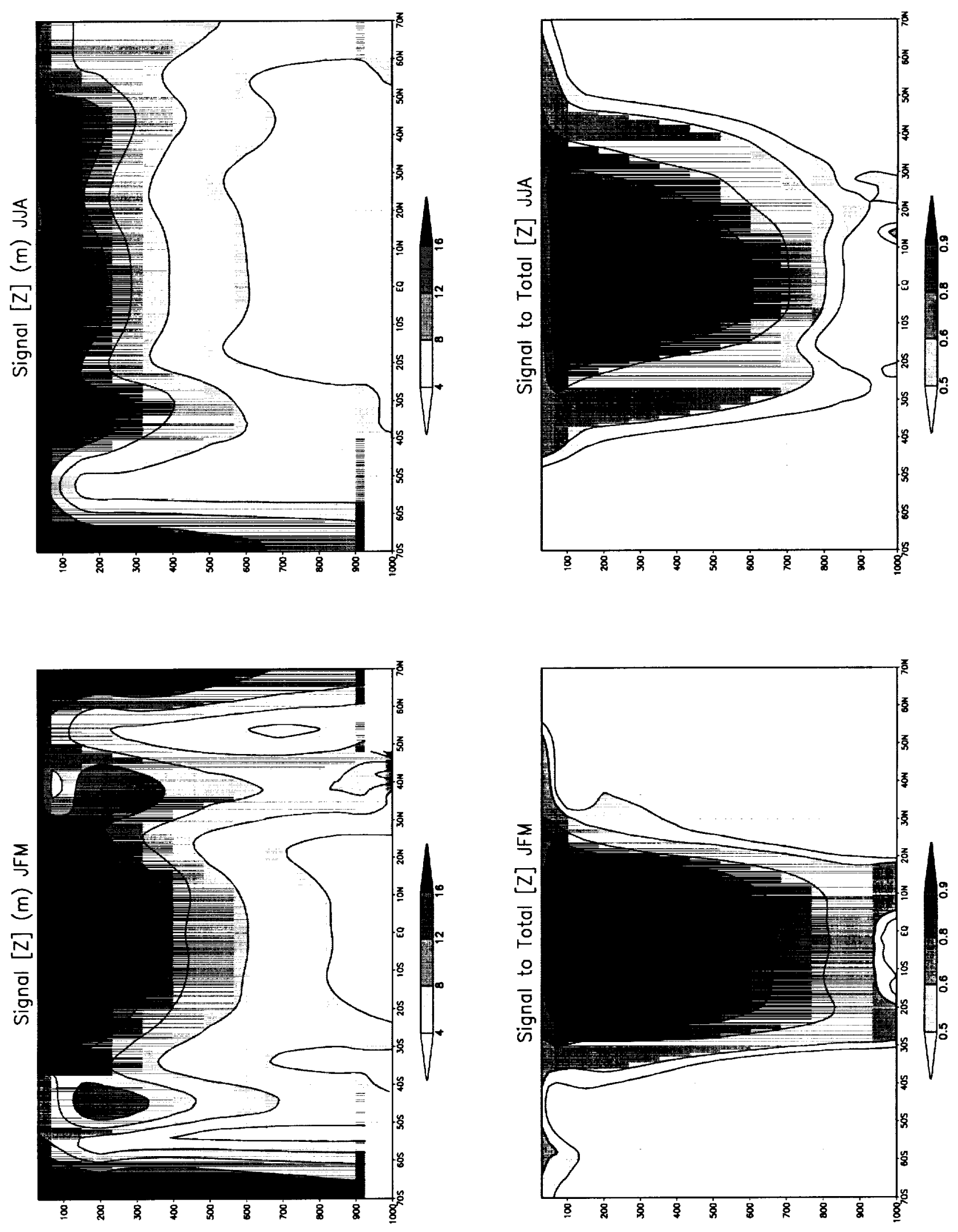

Fig 3 
EOF 1 Zonal mean Hght: JJA

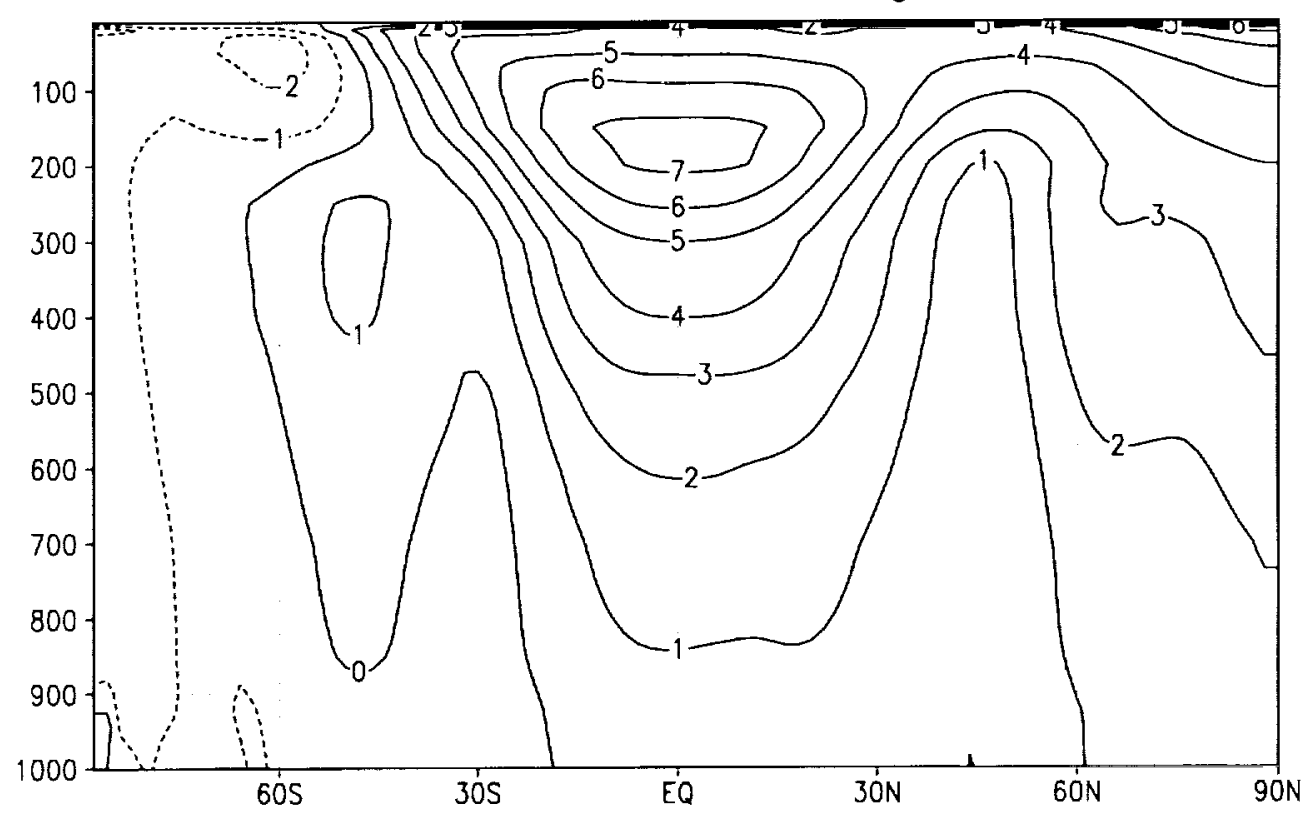

EOF 2 Zonal mean Hght: JJA

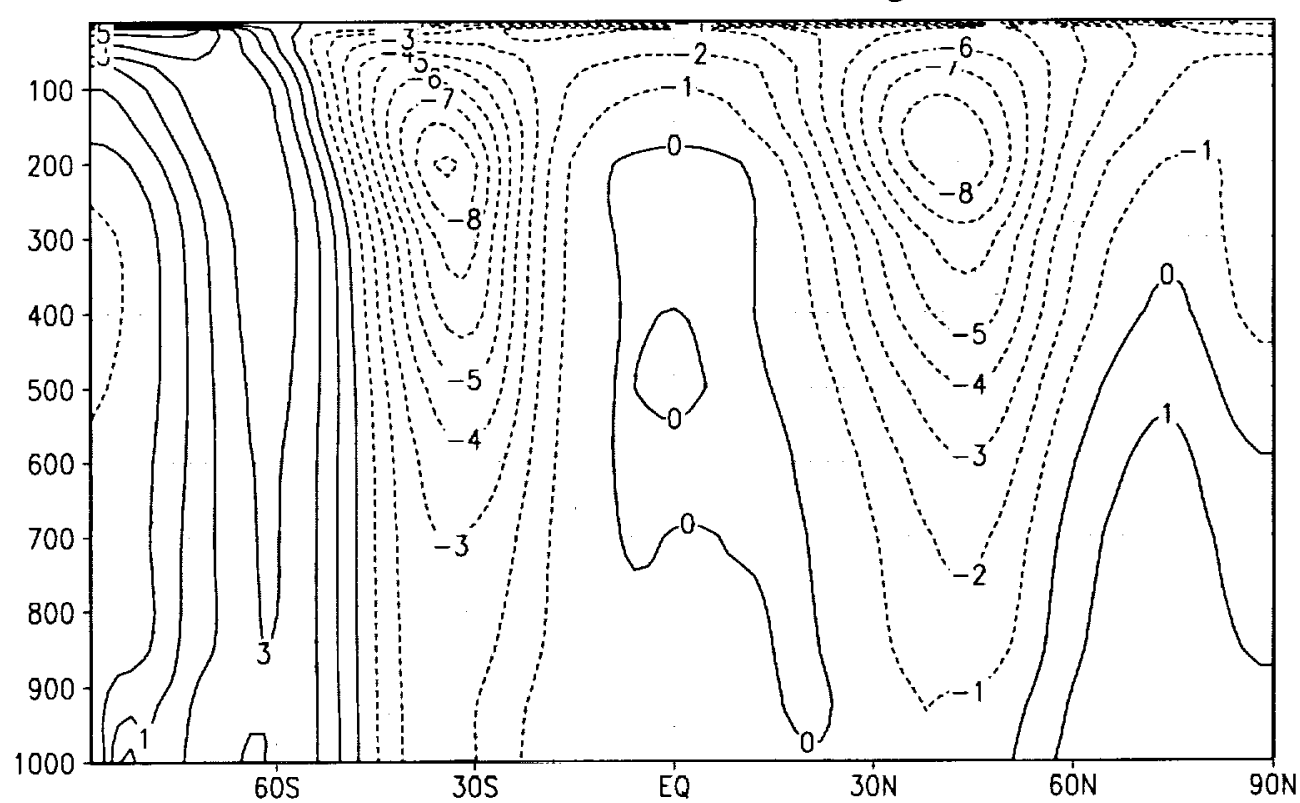



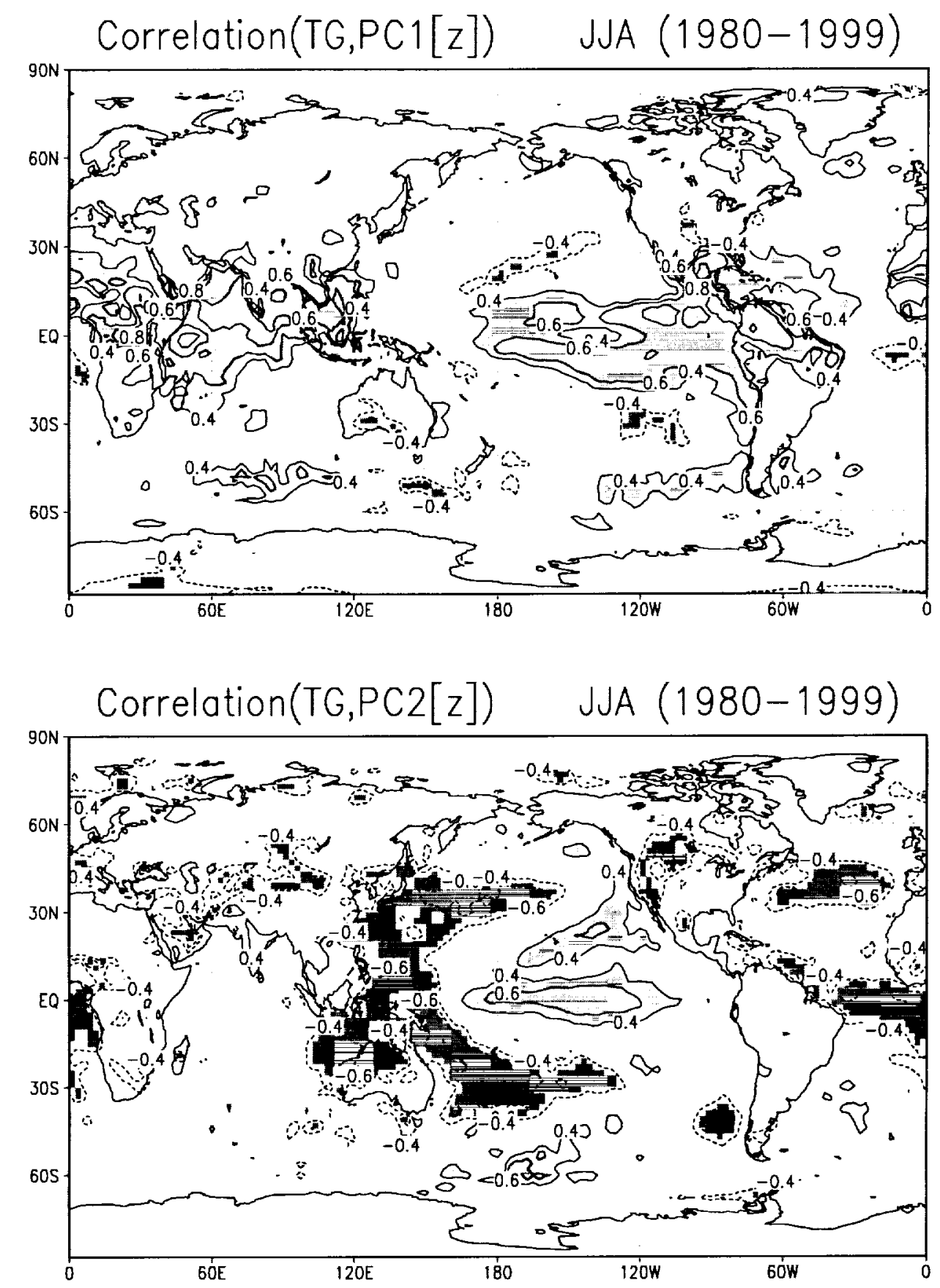
EOF 1 rotated (22\%): SST JJA

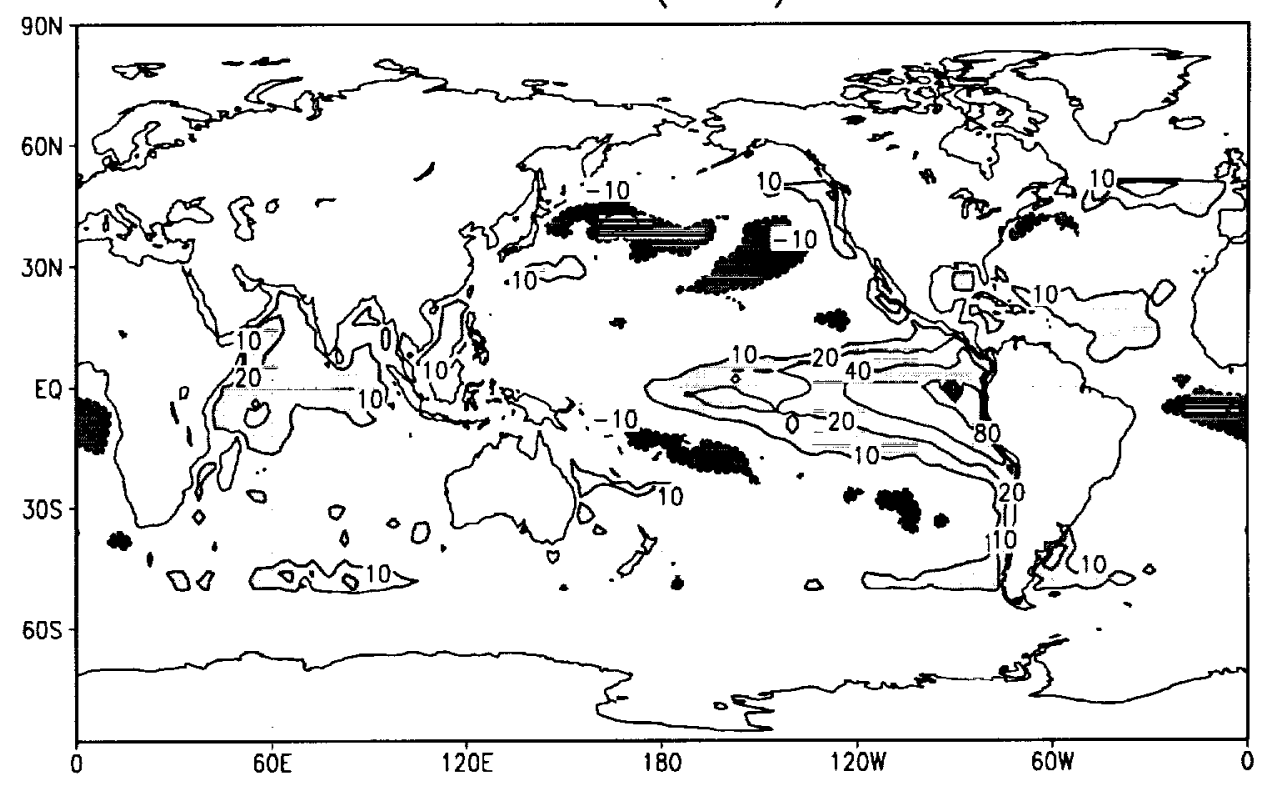

EOF 2 rotated (19\%): SST JUA

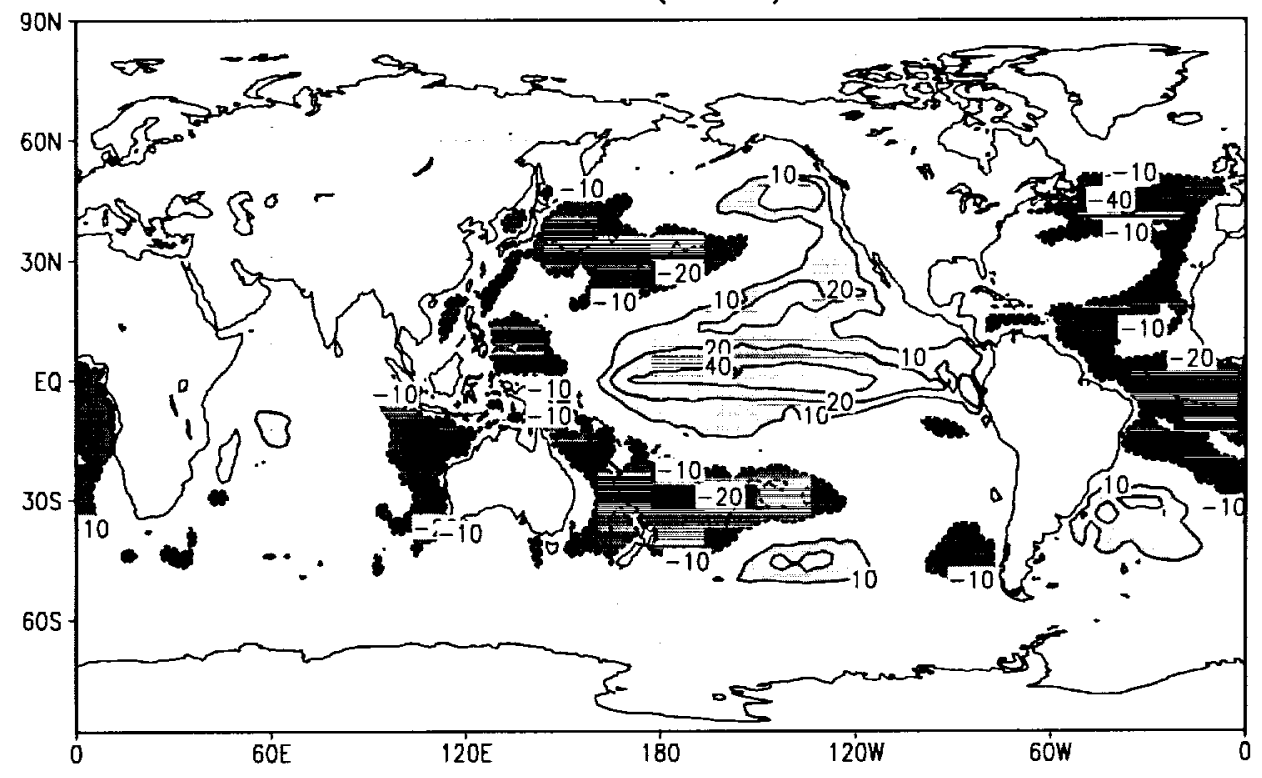

Fig 6 


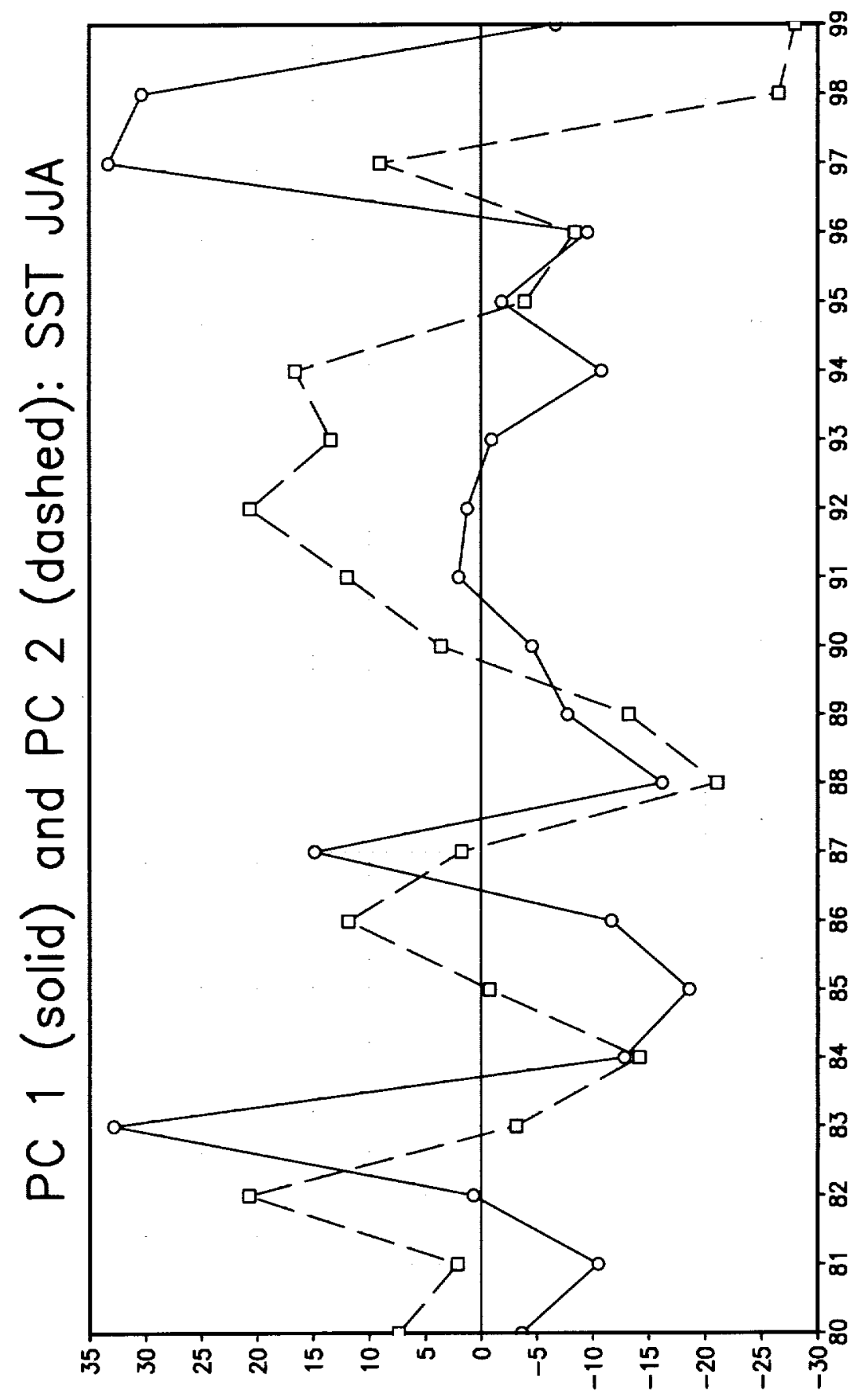

Fig7. 

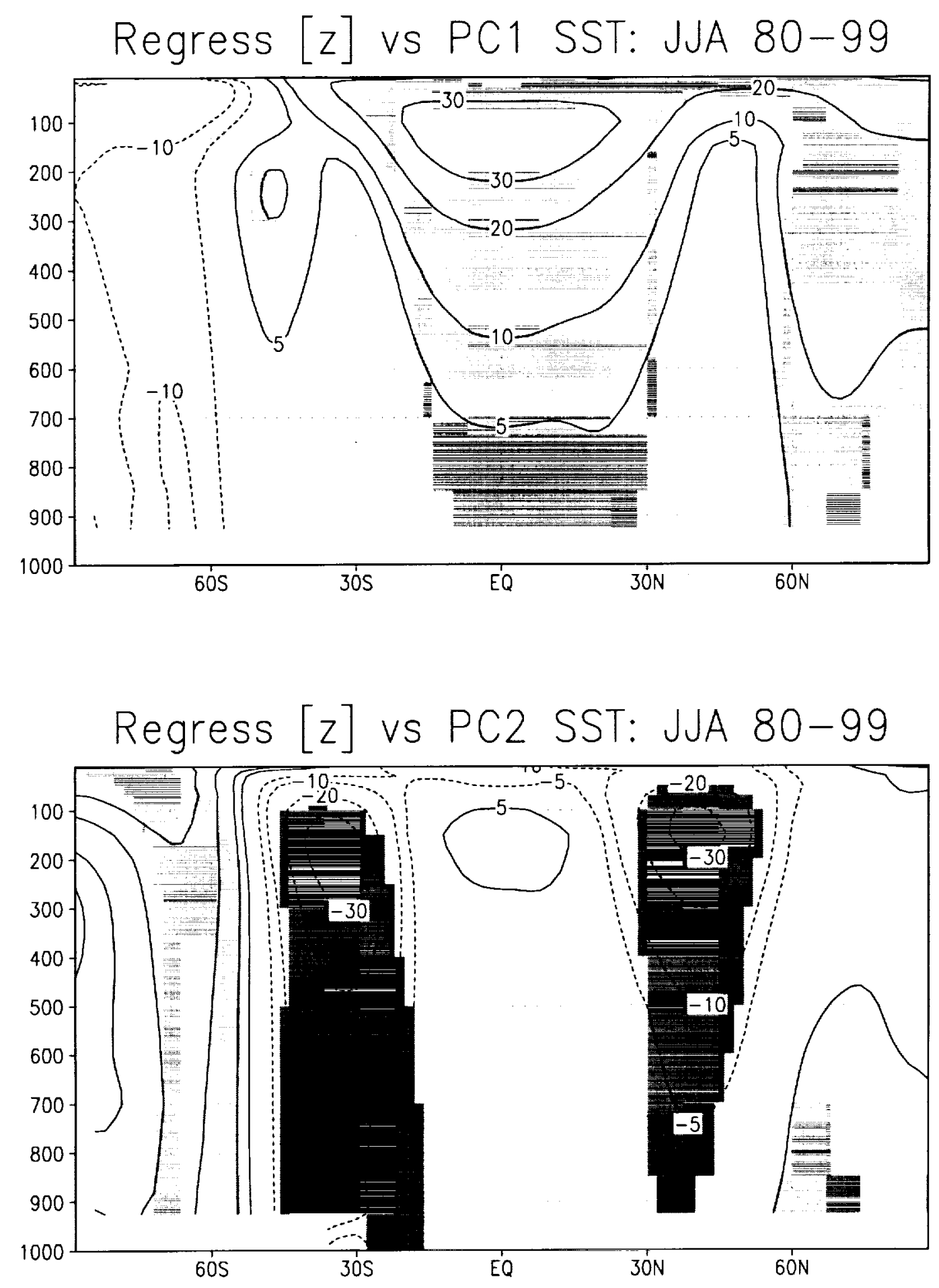

Figg 

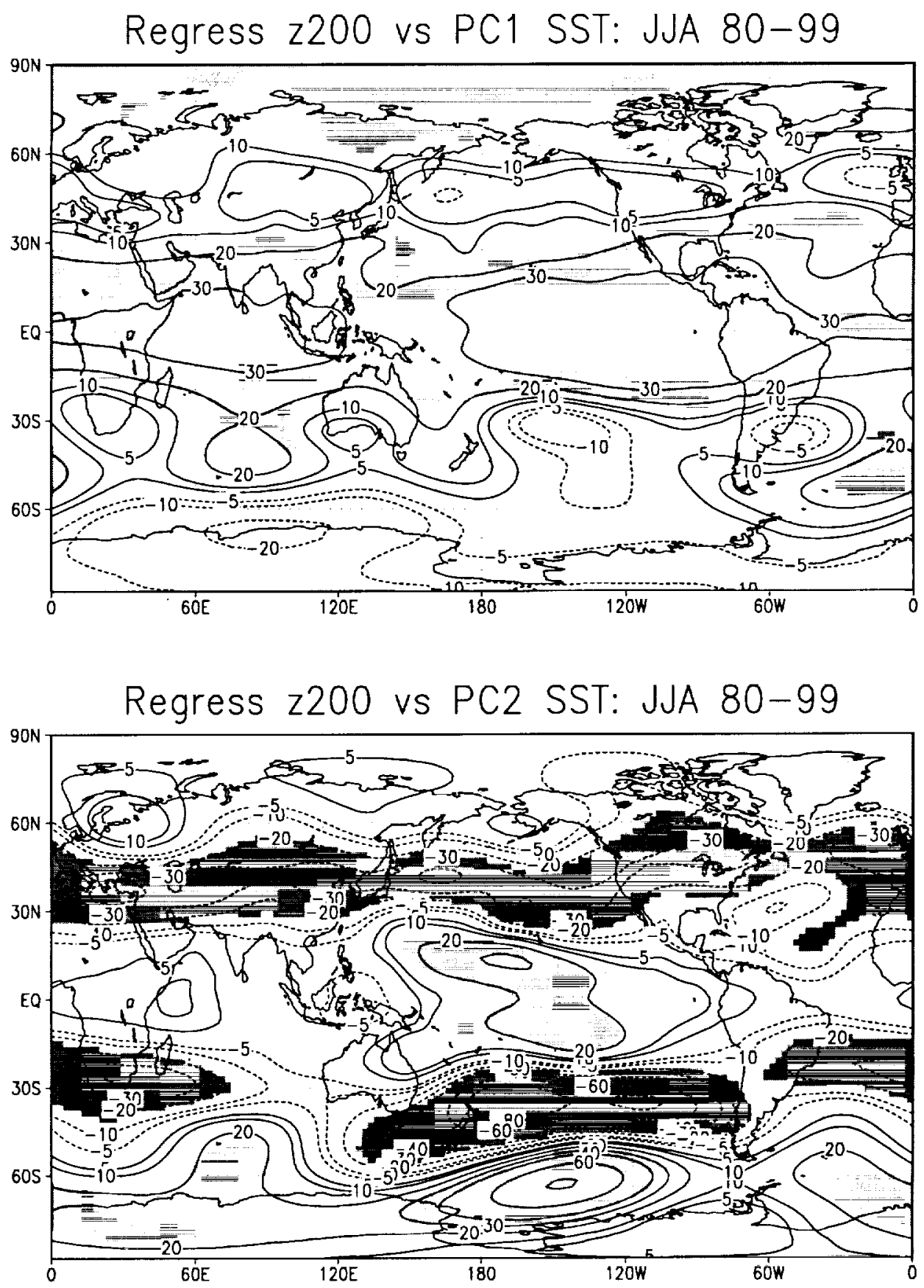

$$
\text { Fig } 9
$$



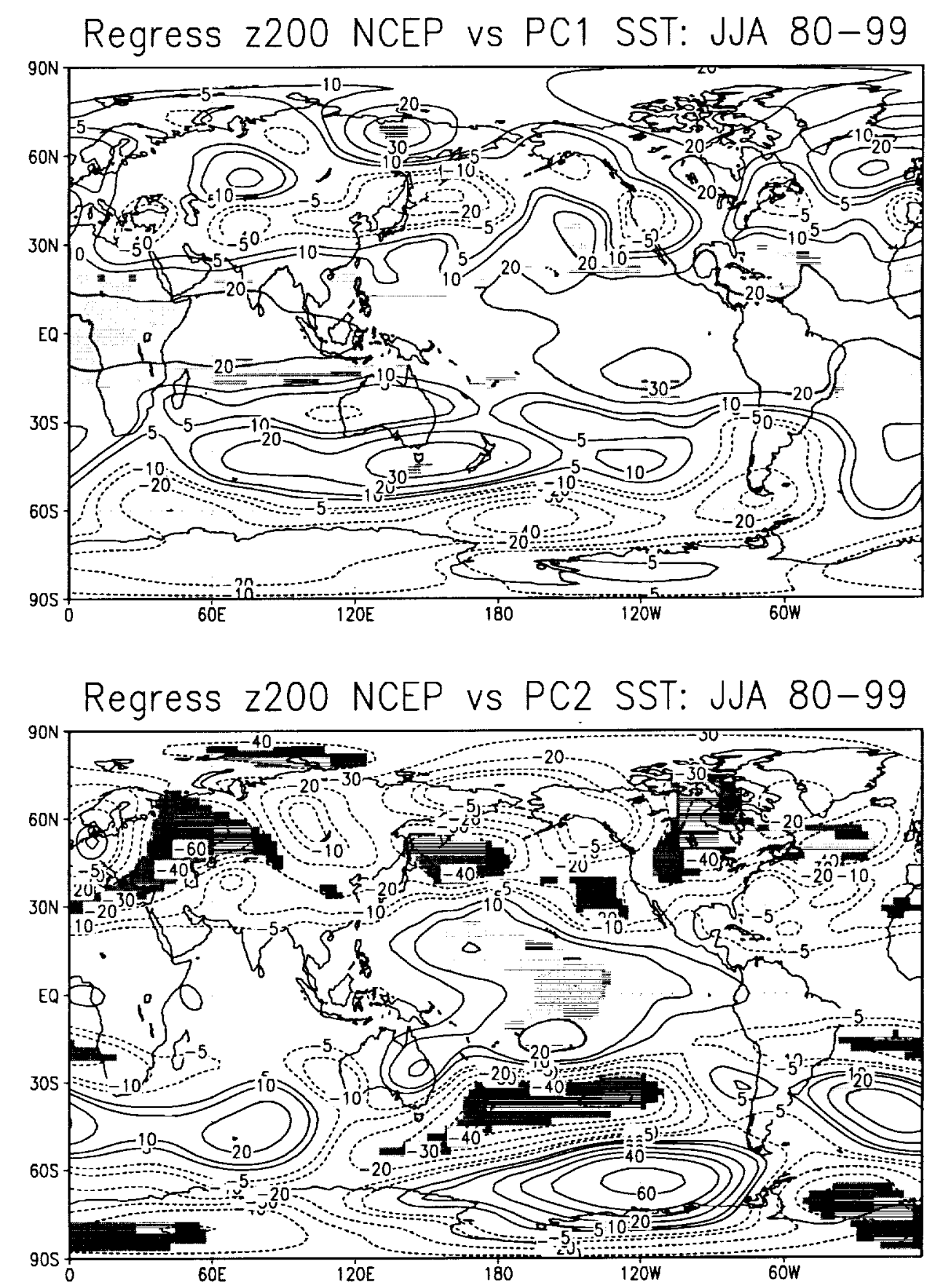

Fig 10 

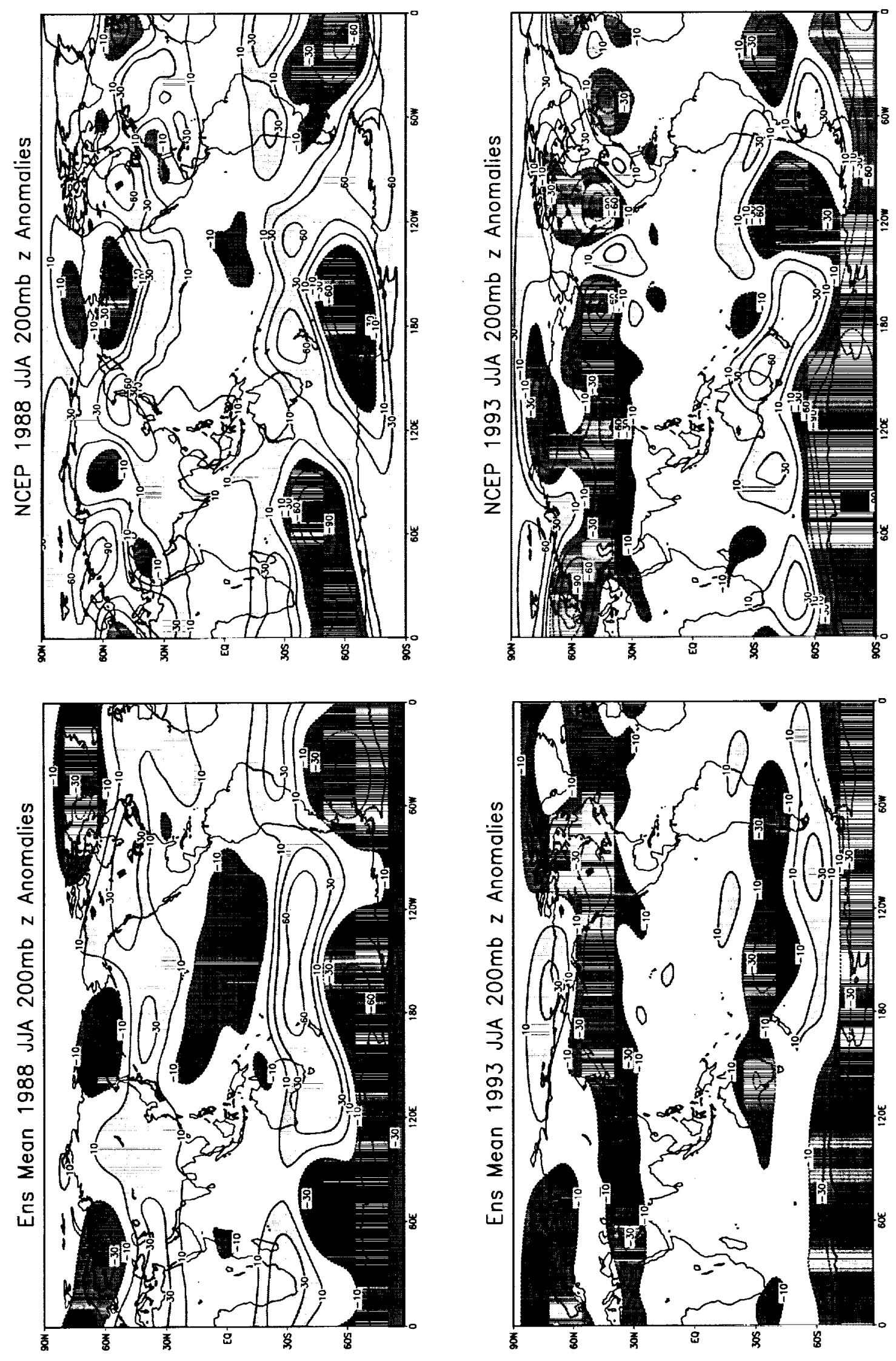

Figll. 
z200 anomaly forced by eof 1

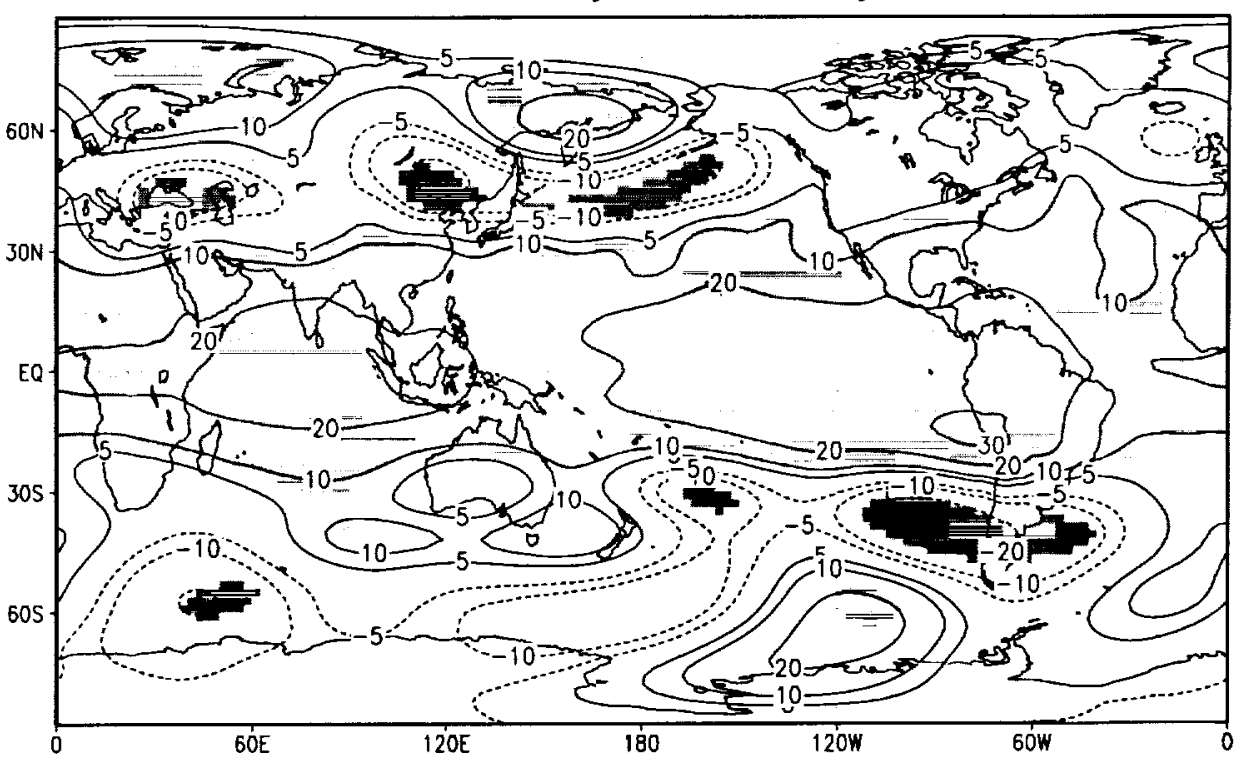

z200 anomaly forced by eof2

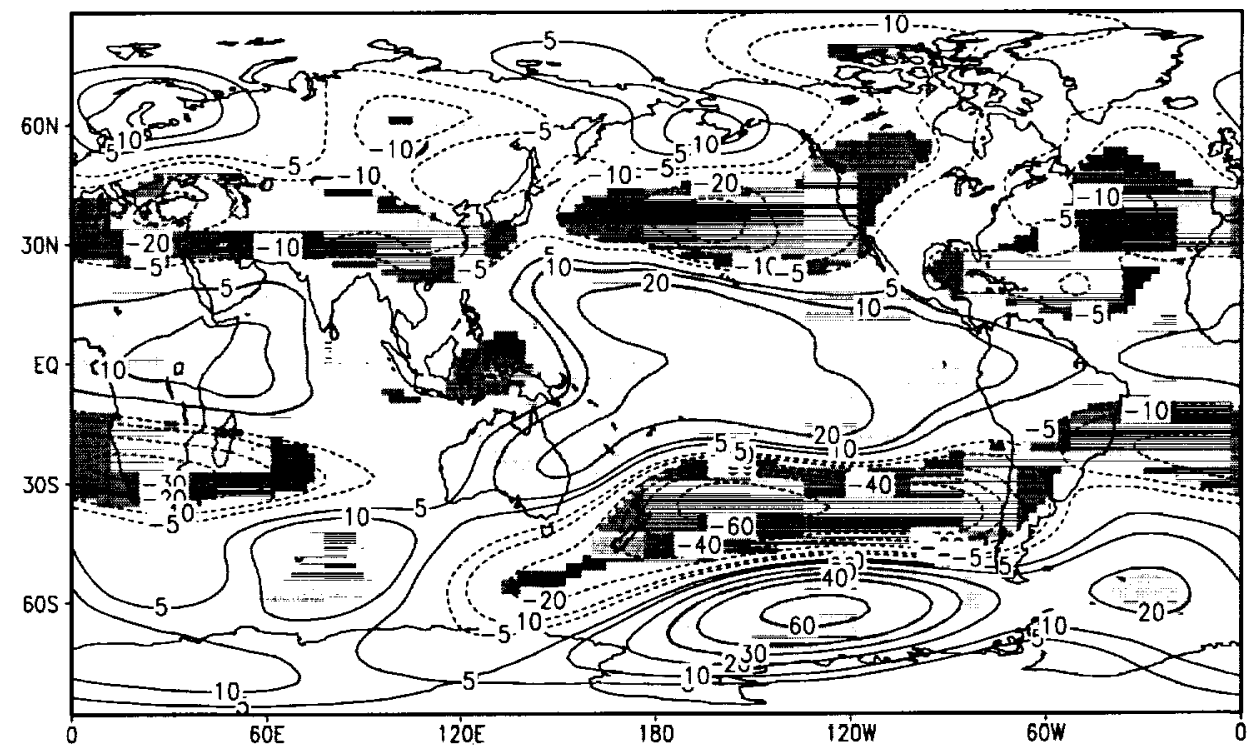

Fig. 12 


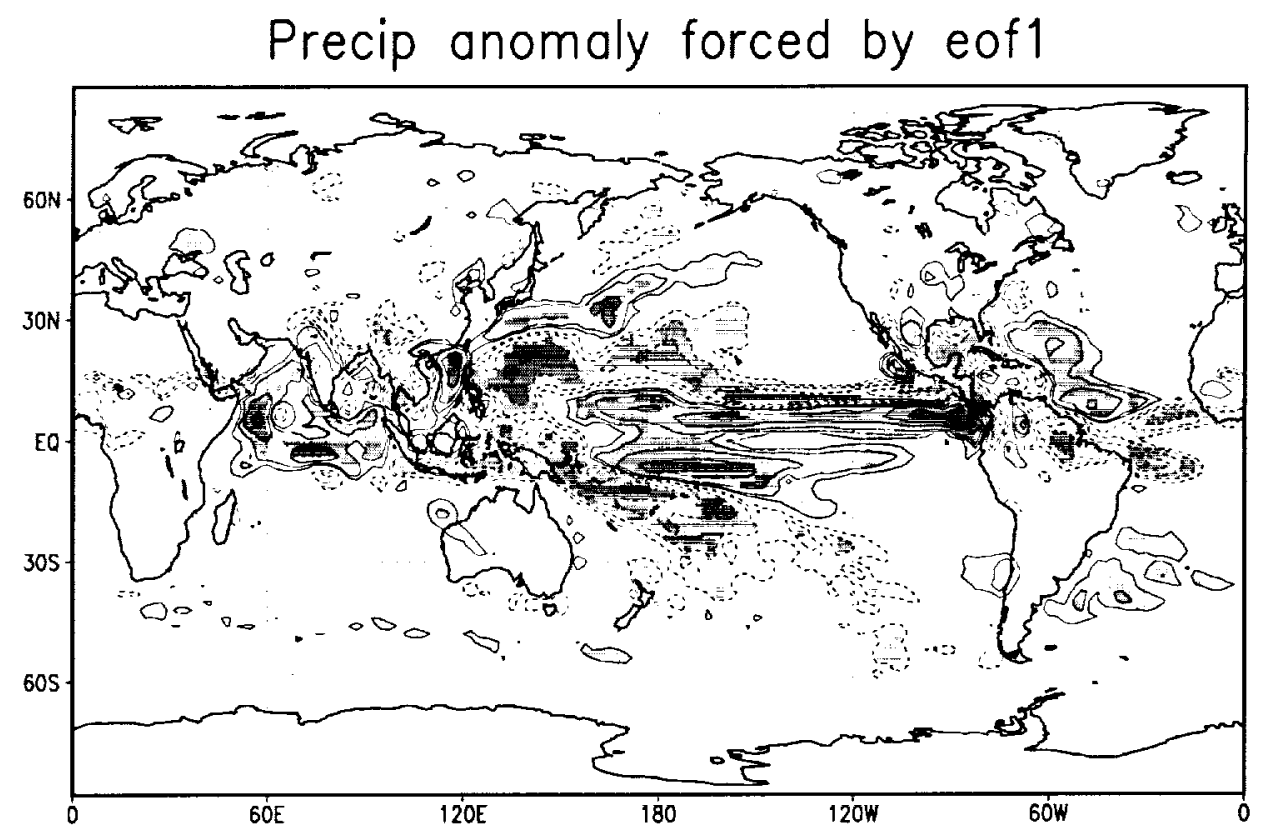

Precip anomaly forced by eof2

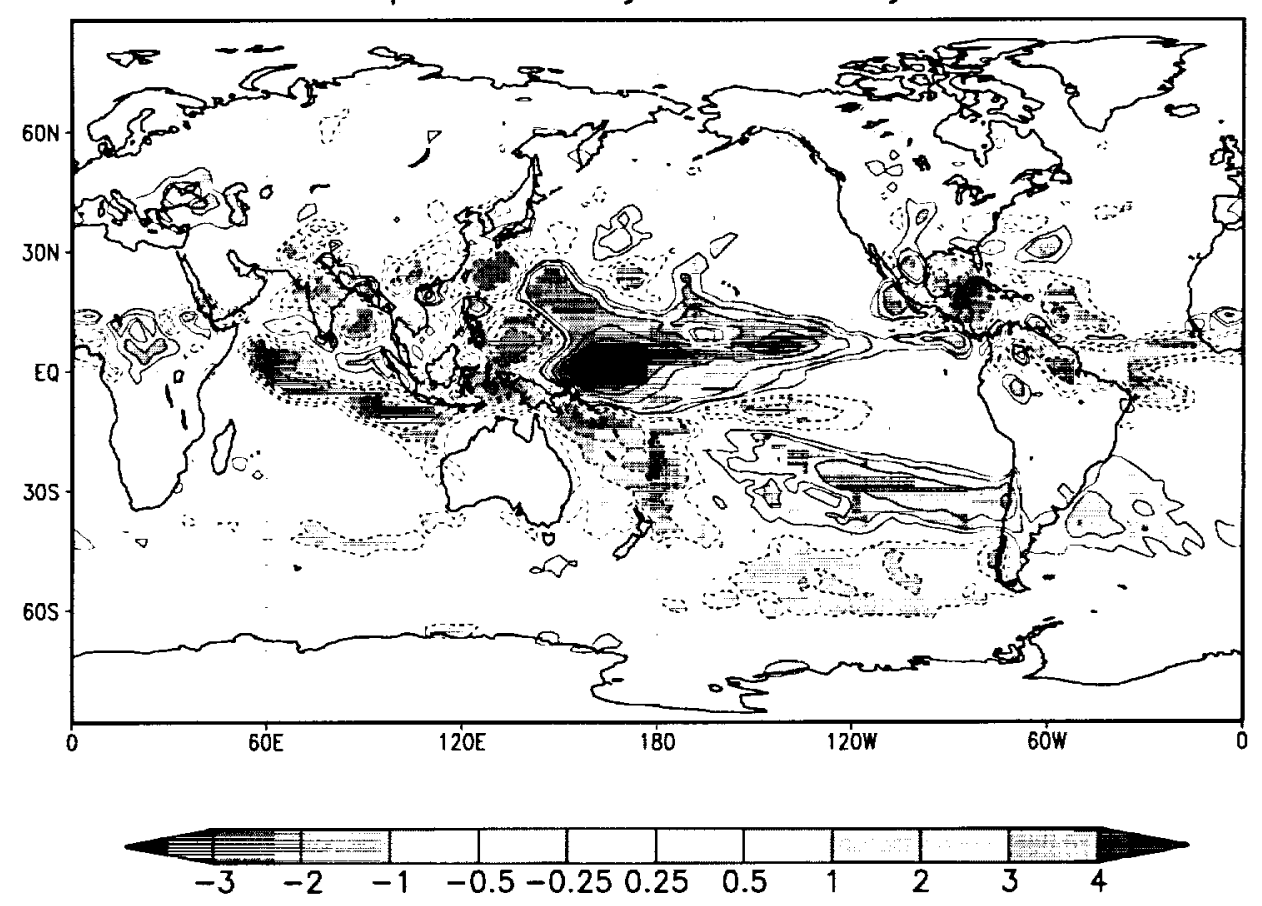

Fig 13. 
Regress Obs Precip vs PC1 SST: JJA 80-99

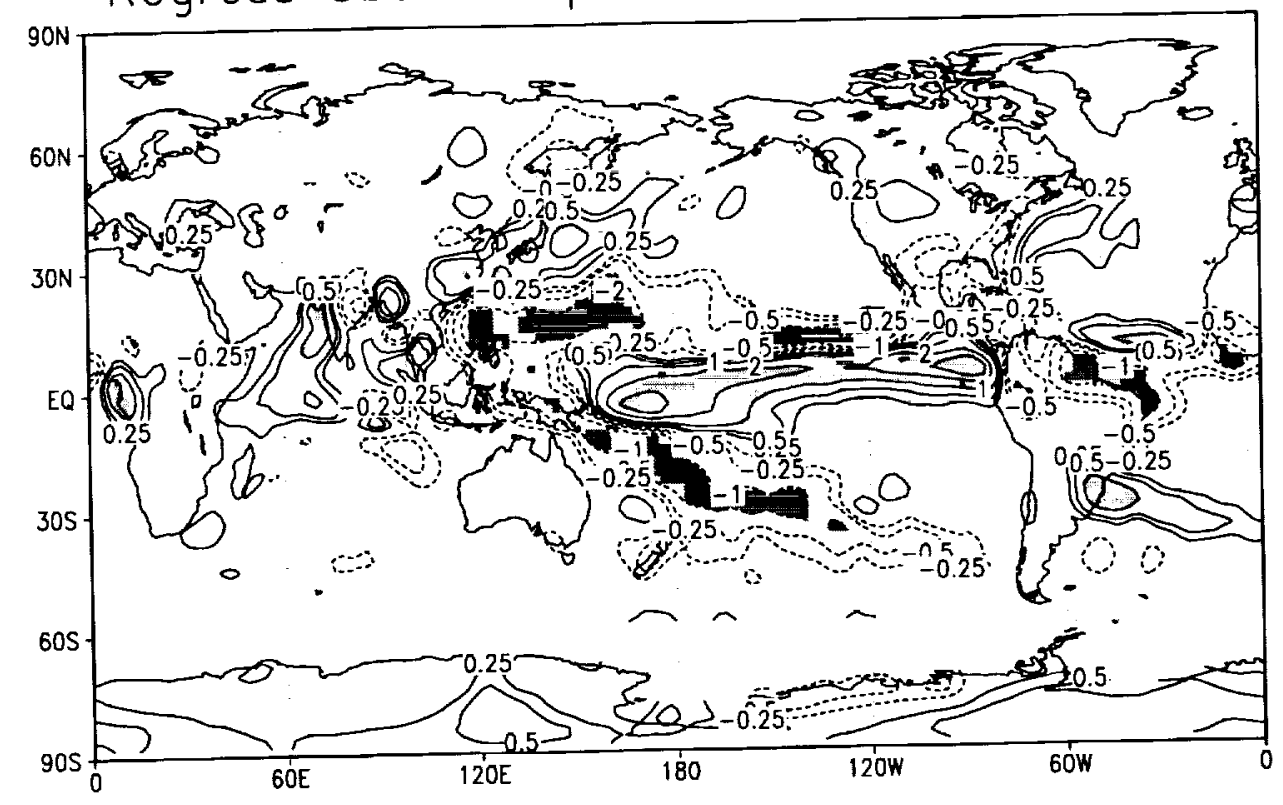

Regress Obs Precip vs PC2 SST: JJA 80-99

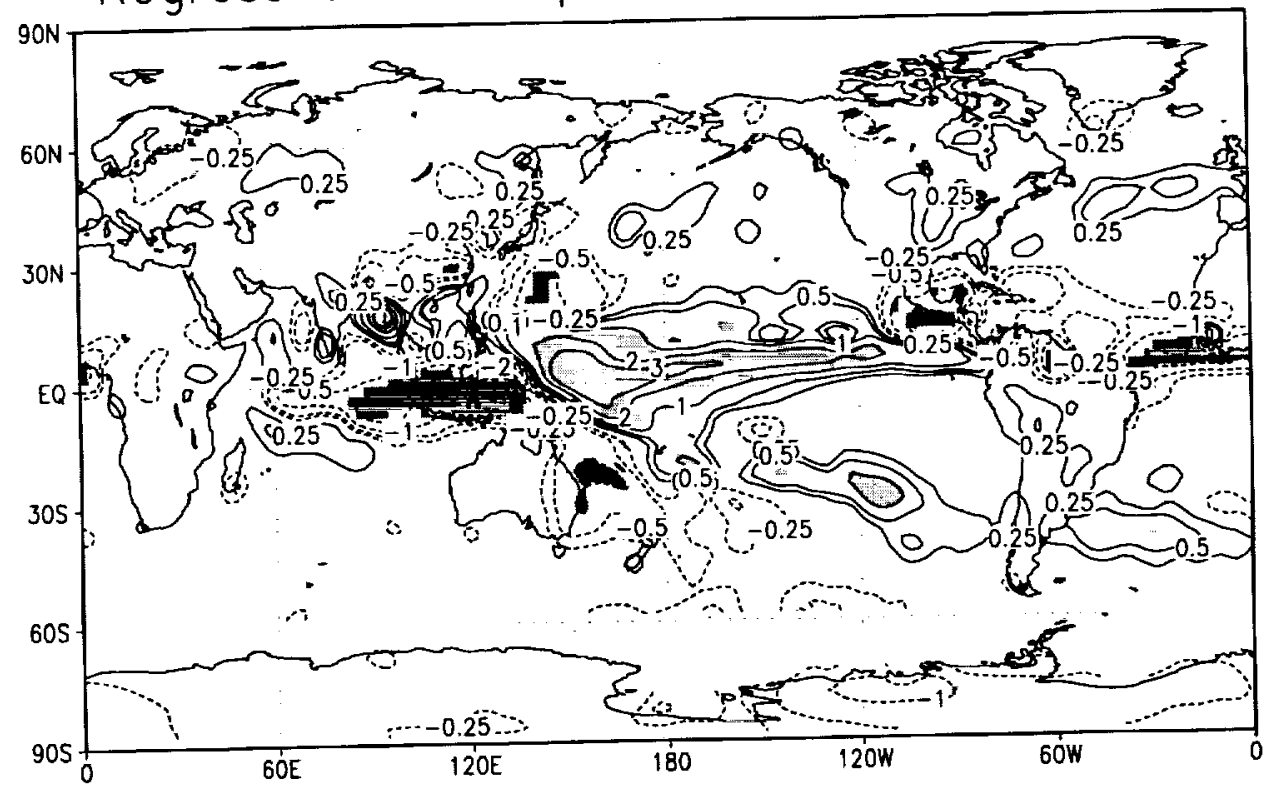

